\title{
Determination of the minimum drop height of the spherical grains in the solution of the treater
}

\author{
Viktor Saitov $^{*}$, Vyacheslav Farafonov ${ }^{1}$, Aleksey Saitov ${ }^{1}$, and Tatyana Malykh ${ }^{1}$ \\ ${ }^{1}$ Vyatka State Agricultural Academy, 133, October ave., Kirov, 610017, Russia
}

\begin{abstract}
One of the main reserves for increasing grain production is the use for sowing high-quality seeds, purified from impurities and pathogens. One of the main ways to protect the seed from various diseases is dressing. The most effective way to protect seeds from disease is wet dressing with the simultaneous release of grain impurities. To develop a device for cleaning and dressing seeds by density using a wet method, an estimate was made of the minimum height of the fall of the grain needed to overcome the surface tension of the liquid. As objects of research, pea seeds were used, having a shape close to a spherical. Therefore, a spherical grains with a density $\rho_{z}=(1.15-1.45) \cdot 10^{3} \mathrm{~kg} / \mathrm{m}^{3}$ and a diameter of $2 r_{z}=$ (3.5-10.9) $\cdot 10^{-3} \mathrm{~m}$ was taken as a model of pea seed. We study the fall of individual spherical grains with minimal $\left(2 r_{z m i n}=3.5 \cdot 10^{-3} \mathrm{~m}\right)$ and maximum $\left.\left(2 r_{z \max }=10.9 \cdot 10^{-3} \mathrm{~m}\right)\right)$ linear dimensions that have a density $\rho_{z}=1.15 ; 1.25$; 1.35 and $1.45 \cdot 10^{3} \mathrm{~kg} / \mathrm{m}^{3}$. Drop occurs on the surface of the water $\left(\rho_{z h}=1.0 \cdot 10^{3} \mathrm{~kg} / \mathrm{m}^{3}\right)$ and the aqueous solution of the etchant $\left(\rho_{z h}=1.03\right.$; $1.06 ; 1.09 ; 1.12$ and $\left.1.15 \cdot 10^{3} \mathrm{~kg} / \mathrm{m}^{3}\right)$, with corresponding coefficients $\sigma$ of surface tension $(0.0727 ; 0.0755 ; 0.0771 ; 0.0786 ; 0.0801,0.0816 \mathrm{~N} / \mathrm{m})$ and hydrodynamic drag coefficients $c=0.4\left(0.5\right.$ for $\rho_{z h}=1.12 \cdot 10^{3}$ and $1.15 \cdot 10^{3}$ $\mathrm{kg} / \mathrm{m}^{3}$ ). The process of dressing grain is considered at a temperature of 20 ${ }^{\circ} \mathrm{C}$. It was established that the minimum drop height $h$ to overcome the surface tension of the dressing solution with all spherical grains should be $15.5 \cdot 10^{-3} \mathrm{~m}$.
\end{abstract}

\section{Introduction}

The main raw material for the production of the most important food products for people and animal feed is grain crops. Therefore, the increase in gross grain harvest is the most important of the challenges facing the agricultural sector of the Russian Federation. One of the main reserves for increasing grain production is the use for sowing high-quality grain material, purified from various impurities and pathogens $[1,2]$.

Therefore, the main task at present is the preparation of high-quality seed material of grain crops for sowing. At the same time, seeds brought to sowing conditions can have both internal and external infection. Sowing with infected seeds leads to the transmission of diseases to vegetative plants and thereby creates and maintains foci of infection in the field. In addition, modern resource-saving technologies make particularly high demands on the

\footnotetext{
* Corresponding author: vicsait-valita@e-kirov.ru
} 
quality of seed preparation and sowing technologies, since minimizing soil cultivation contributes to the accumulation and survival of phytopathogens and phytophages in the upper soil layer and significantly complicates the passage of the most vulnerable period from seed germination to formation of full seedlings. Therefore, the treatment of seeds with protective and stimulating drugs is a mandatory measure of intensive technology in crop production [3-5].

One of the main ways to protect the seed from various diseases, such as root rot, mold, septoria, snow mold, from smut diseases and sclerotia, is dressing. Simultaneously with the use of treating agents of a wide spectrum of action for the treatment of seeds, it is recommended to use plant growth regulators and microelements, which at appropriate doses for certain crops stimulate the development of plants and increase their productivity [6-9].

For seed dressing, use dry, semi-dry and wet methods. The simplest method is dry dressing, which has a number of disadvantages: the drug is not evenly distributed on the seeds and poorly held on them, and high dustiness is created at the treatment sites. A semidry method involves etching with liquid pesticides used at a low rate of consumption of drugs with and without water. Wet dressing is carried out mainly by watering or soaking the seed with dilute aqueous solutions or a suspension of wettable powders [8,9].

Currently, seed treatment is most often performed by universal dressing machines: PSH-5, PS-10, PS-10A, Mobitox-super and others. They can be used for seed treatment before sowing with bacterial preparations and growth stimulants, as well as for mixing seeds with micronutrient fertilizers in a semi-dry way. These machines are complex in design, have working auger-type organs that cause increased trauma and crushing of seed material. In addition, these machines have an installed power of 2.5-8.0 kW, which significantly increases the specific energy consumption when performing the process.

Moreover, even in a well-cleaned seed, after repeated transportation, grain fines are again formed [10]. Therefore, at the end of the transport path, to prevent dust from entering the seed dresser, it is necessary to further clean the seed with an air-sieve grain cleaning machine [11-19].

Wet treatment of seed with chemical dressing is carried out for integrated plant protection. It allows you to protect seeds and seedlings from pests that infect seeds, roots and terrestrial parts of plants in the early stages of development. This method provides a deeper and more complete penetration of the treating solution into the seeds and their more complete disinfection from infection. There is no air pollution.

Therefore, the development of a non-complicated wet seed dressing machine, having a low energy consumption of the technological process in comparison with existing grain dressing machines, and including the function of removing grain fines, is an urgent task.

When developing such a device, studies are needed to justify the structural and technological parameters of its main working bodies, one of which is the height $h$ of the location of the feed hopper with seeds relative to the surface of the aqueous solution of the etchant in the bath of this device [20].

\section{Materials and methods}

As objects of research, pea seeds were used, having a spherical shape (ball grains), with a density $\rho_{z}=(1.15-1.45) \cdot 10^{3} \mathrm{~kg} / \mathrm{m}^{3}$ and a diameter of $2 r_{z}=(3.5-10,9) \cdot 10^{-3} \mathrm{~m}$.

The fall of individual ball grains with minimal $\left(2 r_{z \min }=3.5 \cdot 10^{-3} \mathrm{~m}\right)$ and maximum $\left(2 r_{z \max }=10.9 \cdot 10^{-3} \mathrm{~m}\right)$ linear dimensions that have a density of $\rho_{z}=1.15 ; 1.25 ; 1.35$ and $1.45 \cdot 10^{3} \mathrm{~kg} / \mathrm{m}^{3}$. Drop occurs on the surface of the water $\left(\rho_{z h}=1.0 \cdot 10^{3} \mathrm{~kg} / \mathrm{m}^{3}\right)$ and the aqueous solution of the etchant $\left(\rho_{z h}=1.03 ; 1.06 ; 1.09 ; 1.12\right.$ and $\left.1,15 \cdot 10^{3} \mathrm{~kg} / \mathrm{m}^{3}\right)$, with corresponding coefficients $\sigma$ of sur- 
face tension $(0.0727 ; 0.0755 ; 0.0771 ; 0.0786 ; 0.0801,0.0816 \mathrm{~N} / \mathrm{m})$ and hydrodynamic drag coefficients $c=0.4\left(0.5\right.$ for $\rho_{z h}=1.12$ and $\left.1.15 \cdot 10^{3} \mathrm{~kg} / \mathrm{m}^{3}\right)$ [21].

The forces, the influence of which can be neglected due to their small values in comparison with the gravity force $m_{z} g$ of the ball grains and the forces of the surface tension of the liquid, are excluded. The minimum height $h$ of the location of the loading hopper, with which the ball grains must come to the surface of the liquid to overcome the forces of surface tension, is determined taking into account the law of conservation of energy.

Data processing for pea grains (ball grains) having a spherical shape when falling into a liquid with a density $\rho_{z h}=(1.0-1.15) \cdot 10^{3} \mathrm{~kg} / \mathrm{m}^{3}$ was carried out using the Microsoft Excel application package from the standard Microsoft Office 2013 suite.

\section{Results and Discussion}

When developing a device for treating ball-shaped seeds (ball grains) with a wet method, it is necessary to determine the height $h$ of the location of the loading hopper relative to the liquid level in the device bath, which is necessary to overcome the surface tension of the liquid.

To determine the minimum height $h$ of falling ball grains onto the liquid surface and to overcome surface tension, it is necessary to take into account the density $\rho_{z}$, linear dimensions (diameter $2 r_{z}$ ) of the kernel and the physical properties of the etchant aqueous solution $\left(\rho_{z h}, \sigma, c\right)$.

The scheme of the forces acting on the ball grains when falling from the outlet of the feed hopper with the feeder and the pickling solution enters the surface is shown in Figure 1.

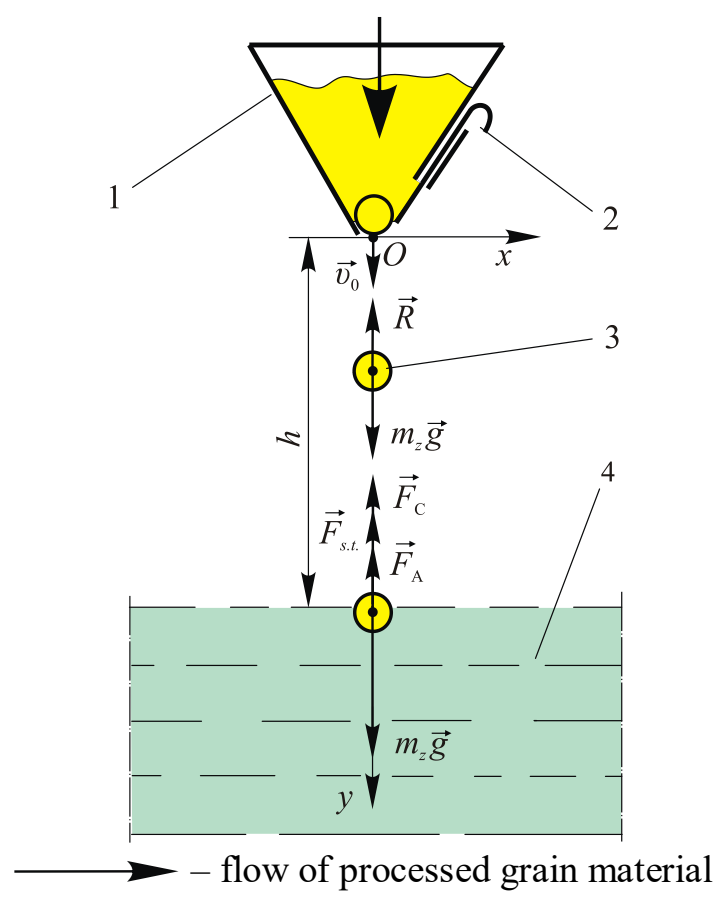

Fig. 1. The scheme of the forces acting on the ball grains when falling from the loading hopper with the feeder and the pickling solution arrives at the surface: 1 - loading hopper with the feeder; 2 - an adjusting gate; 3 - caryopsis; 4 - a bath with a solution of treater 
Compare the force $R$ of the air resistance to the movement of the grain with the force $m g$ of gravity of the grain, with its initial speed $v_{0}$ equal to zero when leaving the loading hopper with a feeder [22]:

$$
R=\frac{m_{\mathrm{z}} g v_{z}^{2}}{v_{\text {vit. }}^{2}}=\frac{2 g}{v_{\text {vit. }}^{2}} \frac{m_{z} v_{z}^{2}}{2}=\frac{2 g}{v_{\text {vit. }}^{2}} m_{z} g h=\frac{2 g h}{v_{\text {vit }}^{2}} m_{z} g
$$

where $m_{z}$ - grain weight, $\mathrm{kg}$;

$g-$ acceleration of gravity, $g=9.81 \mathrm{~m} / \mathrm{s}^{2}$;

$v_{\text {vit. }}$ - grain flow rate, $\mathrm{m} / \mathrm{s}$;

$v_{z}$ - grain fall rate, $\mathrm{m} / \mathrm{s}$;

$h$ - the height of the outlet of the feed hopper with the feeder relative to the level of the solution of the treater, $m$.

In preliminary experiments, the immersion of grains in water was observed at falling heights $h==(1.0-5.0) \cdot 10^{-2} \mathrm{~m}$. Therefore, in the calculations we take these values of height and velocity $v_{\text {vit }}==7.0-17.0 \mathrm{~m} / \mathrm{s}$ of pea grain soaring.

The resistance force air grows (1) as it drops from zero to the maximum possible value of the force $R$ on the surface of the rebar solution, which will be $(0.017-2.0) \cdot 10^{-2} m_{z} g$. It is much less than the gravity force $m_{z} g$ of the ball grains. Therefore, when evaluating the height $h$, the force $R$ of the air resistance will not be taken into account.

Consider the fall of a ball kernel having a diameter of $2 r_{z}$, with complete immersion in the liquid and stop (Figure 1).

The potential energy when the ball grains fall on the surface of the liquid will go into kinetic energy, which, when fully entering the treater solution and stopping, will be completely spent on working against the force $F_{\text {s.t. }}$ the surface tension of the fluid, the Archimedes force $F_{\mathrm{A}}$ and the hydrodynamic drag force $F_{\mathrm{C}}$ arising during turbulent motion due to the pressure difference in front of and behind the ball grains [23].

When the ball grains fall into the treating solution (Figure 2), the work $A_{\mathrm{p}}$ against the force $F_{\text {s.t. }}$ the surface tension of the liquid is determined by the area $\Delta S$ of the surface of the ball [22]:

$$
A_{\mathrm{p}}=\sigma \cdot \Delta S=4 \pi r_{z}^{2} \sigma
$$

where $\sigma$ - the coefficient of surface tension of the solution of the treater, $\mathrm{N} / \mathrm{m}$;

$\Delta S$ - the area by which the free surface of the etchant solution has increased as a result of the entry of ball grains into it, $\mathrm{m}^{2}$.

The force $F_{\mathrm{A}}(y)$ of Archimedes when immersing the ball grains in the etchant solution on the ball segment of height $y$ is equal to (Figure 2):

$$
F_{\mathrm{A}}(y)=\Delta m_{z h} g=\pi y^{2}\left(r_{z}-1 / 3 y\right) \rho_{z h} g
$$

where $\Delta m_{z h}$ - the mass of the column of the dressing solution of height $y$, displaced by part of the ball grains that entered the liquid, $\mathrm{kg}$;

$\rho_{z h}$ - the density of the aqueous solution of the treater $\mathrm{kg} / \mathrm{m}^{3}$.

Then the work of $A_{\mathrm{A}}$ against the force of Archimedes $F_{\mathrm{A}}$ for the ball kernel in differential form is written as follows:

$$
d A_{\mathrm{A}}=F_{\mathrm{A}}(y) d y=\pi y^{2}(r-1 / 3 y) \rho_{z h} g d y .
$$




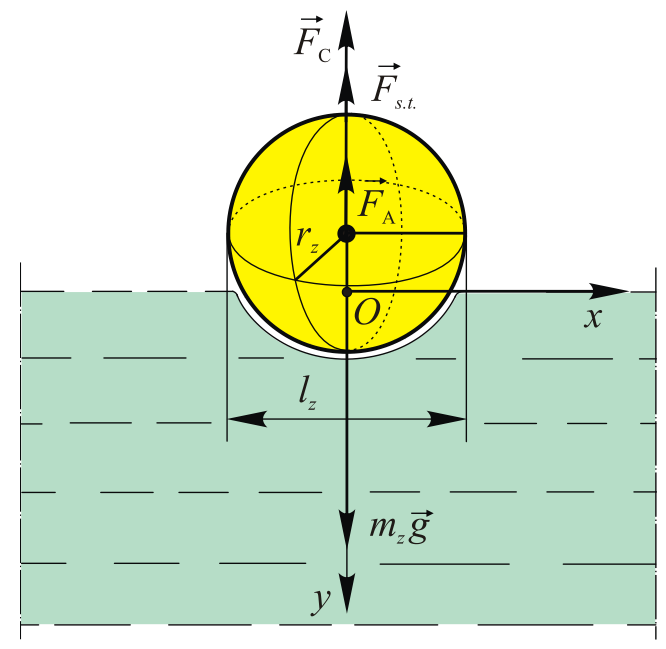

Fig. 2. The scheme of forces acting on the ball grains upon receipt of the etchant solution on the surface.

Integrating expression (4) in the range from 0 to $2 r_{z}$, we obtain

$$
A_{\mathrm{A}}=\int_{0}^{l_{z}} d A_{\mathrm{A}}=\pi \rho_{z h} g \int_{0}^{2 r_{z}} y^{2}\left(r_{z}-1 / 3 y\right) d y=\frac{4 \pi r_{z}^{4} \rho_{z h} g}{3}=\frac{\rho_{z h} r_{z}}{\rho_{z}} m_{z} g .
$$

The force $F_{\mathrm{C}}$ of hydrodynamic resistance acting on a spherical grain when it is immersed in an aqueous solution of the etchant is equal to [21]:

$$
F_{\mathrm{C}}=c S \frac{\rho_{z h}}{2} v_{z}^{2}
$$

where $c$ - the coefficient of hydrodynamic resistance of the aqueous solution of the treating agent when a ball kernel is immersed in it, depending on the geometric shape of the kernel, speed and viscosity of the liquid;

$S$ - projection area of the body (ball grains) on a plane perpendicular to the direction of movement of the grains (mid-section), $\mathrm{m}^{2}$.

When the ball grains fall, the work against the force $F_{\mathrm{C}}$ of the hydrodynamic resistance specified consists of two parts. When immersing the ball grains from the moment of touching the surface of the aqueous solution of the dresser to a depth equal to the radius of the ball $r_{z}$, for the mid-section we take the variable cross-sectional area of the grains at the level of the surface of the solution. We consider the speed of the ball grains constant, thereby finding the overestimated value $A_{1 \mathrm{C}}$ of work:

$$
A_{1 \mathrm{C}}=\int_{0}^{r_{z}} F_{\mathrm{C}} d y=c \frac{\rho_{z h}}{2} v_{3}^{2} \int_{0}^{r_{z}} S d y=c \frac{\pi \rho_{z h} r_{z}^{2}}{2} v_{z}^{2} \int_{0}^{r_{z}}\left(1-\frac{y^{2}}{r_{z}^{2}}\right) d y=\frac{c \rho_{z h}}{2 \rho_{z}} m_{z} g h .
$$

With further immersion of the ball grains in the aqueous solution of the treating agent, the mid-sectional area is constant and equal $\pi r_{z}^{2}$, then: 


$$
A_{2 \mathrm{C}}=F_{\mathrm{C}} r_{z}=c S \frac{\rho_{z h}}{2} v_{z}^{2} r_{z}=\frac{\pi c b_{z}^{2} \rho_{z h} v_{z}^{2} r_{z}}{2}=\frac{3 c \rho_{z h}}{4 \rho_{z}} m_{z} g h
$$

The full work against the force $F_{\mathrm{C}}$ of hydrodynamic drag will be taken into account by a factor of 0.5 due to the overestimated value of this work obtained by formulas (7) and (8)

$$
A_{\mathrm{C}}=\frac{1}{2}\left(A_{1 \mathrm{C}}+A_{2 \mathrm{C}}\right)=\frac{c \rho_{z h}}{4 \rho_{z}} m_{z} g h+\frac{3 c \rho_{z h}}{8 \rho_{z}} m_{z} g h=\frac{5 c \rho_{z h}}{8 \rho_{z}} m_{z} g h
$$

When the ball grains enter the treater water solution completely and stop (Figure 3), it needs potential energy at the outlet of the loading hopper:

$$
E=m_{z} g h+2 m_{z} g r_{z}
$$

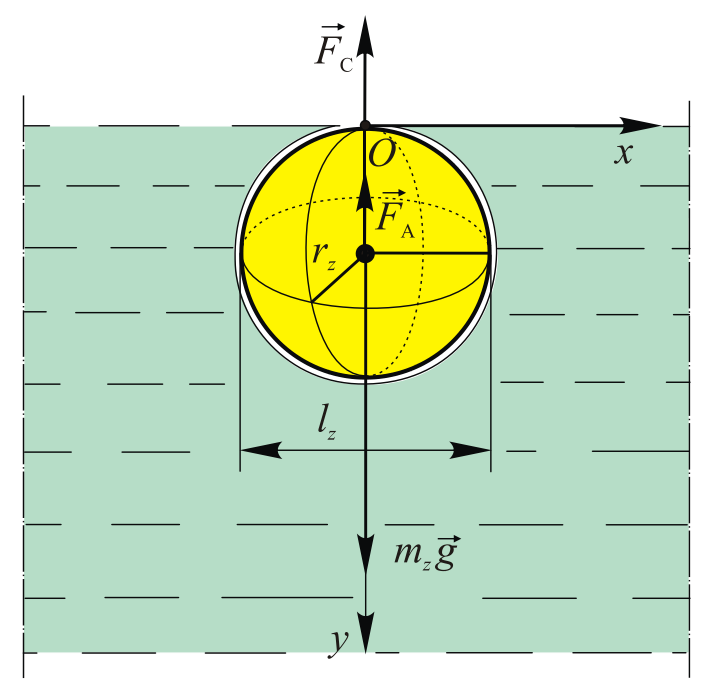

Fig. 3. The scheme of forces acting on the ball grains when completely immersed in the solution of the treater.

The equation of the law of conservation of energy, describing the fall of the ball grains and overcoming the surface of the liquid, taking into account expressions (2), (5), (9) and (10), will have the form:

$$
m_{z} g\left(h+2 r_{z}\right)=4 \pi r_{z}^{2} \sigma+\frac{\rho_{z h}}{\rho_{z}} m_{z} g r_{z}+\frac{5 c \rho_{z h}}{8 \rho_{z}} m_{z} g h
$$

Transforming equation (11), we determine the minimum drop height of the ball grains necessary to overcome the surface tension of the liquid

$$
h=\frac{8}{8 \rho_{z}-5 c \rho_{z h}}\left[\frac{3 \sigma}{g r_{z}}+\rho_{z h} r_{z}-2 \rho_{z} r_{z}\right] \text {. }
$$

We carry out a qualitative analysis of the dependence (12) of the minimum drop height $h$ of the ball grains necessary to overcome the surface tension of the liquid. With an increase in the density $\rho_{z}$ of the kernel, while the values of the other parameters $\left(r_{z}, \rho_{z h}, c\right.$ and 
$\sigma)$ remain unchanged, the minimum height $h$ decreases. Because with an increase in the density $\rho_{z}$ of the grain, its mass and potential energy increase, if the height $h$ is left unchanged, corresponding to a lower density. Therefore, with an increase in the density $\rho_{z}$ of the caryopsis, its lower potential energy (minimum height $h$ ) is required, which is necessary to overcome the surface tension of the etchant aqueous solution.

The same analysis shows that with increasing density $\rho_{z h}$ of the liquid, the minimum height $h$ necessary to overcome its surface tension increases. Because, with an increase in the fluid density $\rho_{z h}$ at constant values of the remaining parameters $\left(r_{z}, \rho_{z}, c\right.$ and $\left.\sigma\right)$, the Archimedes force $F_{\mathrm{A}}$ and the hydrodynamic resistance force $F_{\mathrm{C}}$ increase (6), and, therefore, work against these forces (5) and (9) necessary for the penetration of the grains into the aqueous solution of the treater. From the law of conservation of energy, it is necessary to increase the potential energy of the grain, and, therefore, increase the minimum height $h$ necessary to overcome the surface tension of the water solution of the etchant with the grain.

With an increase in the diameter of $2 r_{z}$ of the ball kernel and falling into the liquid, while the values of the other parameters $\left(\rho_{z}, \rho_{z h}, c\right.$ and $\left.\sigma\right)$ remain unchanged, the minimum height $h$ decreases. Physically, this is due to the fact that with an increase in the diameter of $2 r_{z}$ of the ball kernel, its volume increases. Consequently, the mass and potential energy increase, if the height $h$ is left unchanged, corresponding to a smaller value of the linear size of the grain. The result is an overestimated value of the potential energy, which must be reduced by reducing the minimum height $h$ of the fall of the grain needed to overcome the surface tension of the liquid.

A quantitative analysis of the obtained dependence (12) was performed. For this, calculations were carried out using the statistical data processing program Microsoft Word 2013. Calculations were made for pea grains having a spherical shape with a density $\rho_{z}=(1.15-$ $1.45) \cdot 10^{3} \mathrm{~kg} / \mathrm{m}^{3}$ and a diameter of $2 r_{z}=(3.5-10.9) \cdot 10^{-3} \mathrm{~m}$. Grains fall into the water solution of the etchant with density $\rho_{z h}=1.0 \cdot 10^{3} \mathrm{~kg} / \mathrm{m}^{3}$ and $1.15 \cdot 10^{3} \mathrm{~kg} / \mathrm{m}^{3}$, with the corresponding surface tension coefficients $\sigma=0.0727$ and $0.0816 \mathrm{~N} / \mathrm{m}$.

The coefficient $c$ of hydrodynamic resistance of the ball grains depends on the Reynolds number, which depends on the geometric shape $\left(r_{z}\right)$ of the grains, its speed $v_{z}$, coefficient $v$ of the kinematic viscosity of the liquid and is in the formula [21]:

$$
\operatorname{Re}=\frac{2 r_{3} v_{3}}{v}
$$

The values of the velocities of ball grains (pea grains) were determined in preliminary experiments in water $v_{z}=(0.1-0.4) \mathrm{m} / \mathrm{s}$. The values of the kinematic viscosity coefficient of the liquid $v=(1.01-1.30) \cdot 10^{-6} \mathrm{~m}^{2} / \mathrm{s}$ are taken from the «Reference to the thermophysical characteristics of food products and semi-finished products», published under the authorship of Chubik I.A. and Maslova A.M. in 1970 in Moscow by the «Food Industry» publishing house. For a specific ball grain, we find the Reynolds number and, according to the graph given in the reference book «Heat Transfer and Hydrodynamic Resistance», published under the authorship of Kutateladze S.S. in 1990 in Moscow by the Energoatomizdat publishing house, we determine the value of the coefficient of hydrodynamic resistance. Upon receipt of the ball grains in the aqueous solution of the etchant with a density $\rho_{z h}=1.0 \cdot 10^{3} \mathrm{~kg} / \mathrm{m}^{3}$, the coefficient $c$ with hydrodynamic resistance is 0.4 , and in the density solution $\rho_{z h}=1.15 \cdot 10^{3} \mathrm{~kg} / \mathrm{m}^{3}$, the coefficient $c=0.5$.

The dependences of the minimum drop height $h$ of the ball kernel on the linear dimensions of $2 r_{z}$ and density $\rho_{z}$ when the etchant enters the solution with a density $\rho_{z h}=1.0 \cdot 10^{3}$ 
$\mathrm{kg} / \mathrm{m}^{3}$

and

$1.15 \cdot 10^{3} \mathrm{~kg} / \mathrm{m}^{3}$ are shown in Figures 4 and 5 .

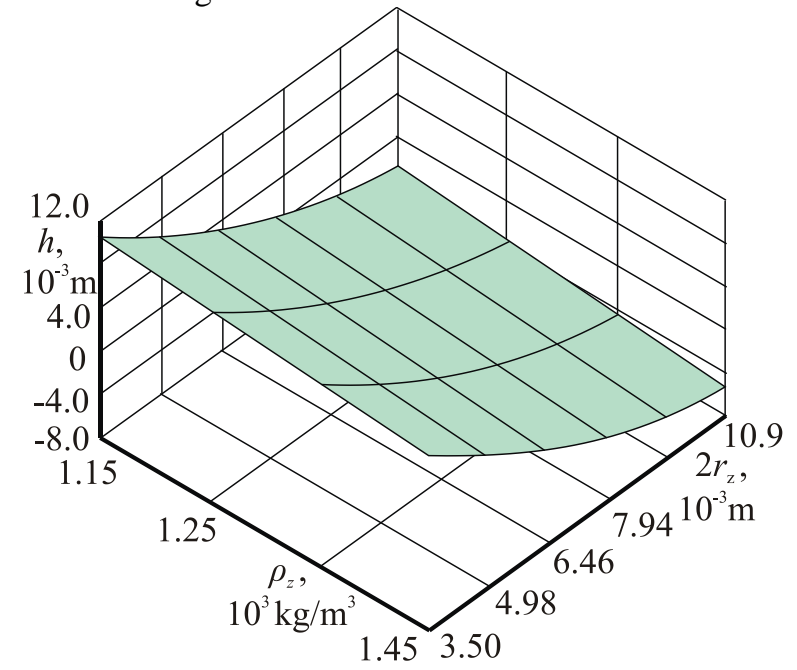

Fig. 4. Dependence of the minimum drop height $h$ of the ball kernel on the linear dimensions of $2 r_{z}$ and density $\rho_{z}$ when the etchant has a density of $\rho_{z h}=1.0 \cdot 10^{3} \mathrm{~kg} / \mathrm{m}^{3}$

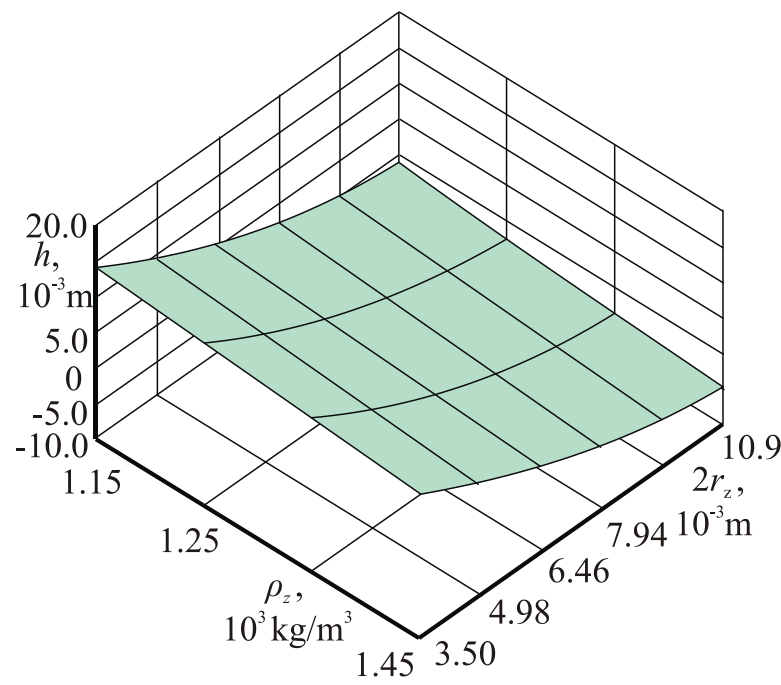

Fig. 5. Dependence of the minimum drop height $h$ of the ball kernel on the linear dimensions of $2 r_{z}$ and density $\rho_{z}$ when the etchant has a density of $\rho_{z h}=1.15 \cdot 10^{3} \mathrm{~kg} / \mathrm{m}^{3}$

From Figures 4 and 5 it follows that with an increase in the density $\rho_{z}$ and diameter $2 r_{z}$ of the ball kernel (pea), the values of its minimum drop height h necessary to overcome the surface tension of the etchant solution decrease. With an increase in the density $\rho_{z h}$ of the liquid, the values of the minimum drop height $\mathrm{h}$ increase. The conclusions of quantitative and qualitative analyzes coincide. For certain values of density $\rho_{z}$ and diameter $2 r_{z}$ of a ball kernel, the minimum height $h$ has zero and negative values. This is because these grains, even placed on the surface of the liquid, overcome surface tension and drown.

When the ball grains enter the water with a density $\rho_{z h}=1.0 \cdot 10^{3} \mathrm{~kg} / \mathrm{m}^{3}$ (Figure 4), the maximum value of the minimum drop height $h$ at the lowest values $\rho_{z}=1.15 \cdot 10^{3} \mathrm{~kg} / \mathrm{m}^{3}$ and $2 r_{z}=3.5 \cdot 10^{-3} \mathrm{~m}$ is $11.6 \cdot 10^{-3} \mathrm{~m}$. For a fixed value of $\rho_{z}=1.15 \cdot 10^{3} \mathrm{~kg} / \mathrm{m}^{3}$, the minimum 
height $h$ necessary to overcome the surface tension of water for ball grains with a diameter of $2 r_{z} \geq 4.14 \cdot 10^{-3} \mathrm{~m}$ is to zero. With an increase in density $\rho_{z}$ to a maximum value of $1.45 \cdot 10^{3} \mathrm{~kg} / \mathrm{m}^{3}$ for ball kernels with a diameter of $2 r_{z} \geq 3.42 \cdot 10^{-3} \mathrm{~m}$, the minimum height $h$ is zero.

With an increase in the density $\rho_{z h}$ of the etchant solution, the value of the minimum drop height $h$ of the ball grains to overcome the surface tension of the solution increases (Figure 5). So, with a solution density $\rho_{z h}=1.15 \cdot 10^{3} \mathrm{~kg} / \mathrm{m}^{3}$ and the lowest physical and mechanical properties of the grain $\left(\rho_{z}=1.15 \cdot 10^{3}\right.$ $\mathrm{kg} / \mathrm{m}^{3}$

and $2 r_{z}=3.5 \cdot 10^{-3} \mathrm{~m}$ ), the maximum value of the minimum height $h$ is $15.5 \cdot 10^{-3} \mathrm{~m}$. The minimum height $h=0$ for kernels with a diameter of $2 r_{z} \geq 4.7 \cdot 10^{-3} \mathrm{~m}$ at $\rho_{z}=1.15 \cdot 10^{3} \mathrm{~kg} / \mathrm{m}^{3}$, and with an increase in the density $\rho_{z}$ of the grain to its maximum values of $1.45 \cdot 10^{3} \mathrm{~kg} / \mathrm{m}^{3}$ minimum height $h=0$ for grains with a $2 r_{z} \geq 3.8 \cdot 10^{-3} \mathrm{~m}$. diameter

\section{Conclusion}

Thus, when the ball grains fall into the aqueous solution of the treating agent, the minimum height $h$ of the location of the outlet of the feed hopper depends on the density $\rho_{z}$ and diameter $2 r_{z}$ of the grain, and also the density of the liquid $\rho_{z h}$. Theoretical formula (12) can be used to develop a machine for wet cleaning of impurities and dressing seeds having a shape close to spherical. When developing a device for cleaning and dressing seeds in a wet way in order to guarantee that all grains can overcome the surface tension of the etchant water solution during the flow of grain, it is also necessary to take into account the appearance of an undesirable cumulative effect and capture of air bubbles by grains.

The study was conducted on the scientific topic «Physics and mathematics modeling of separation of grain materials» of the Department of Mathematics and Physics of the Federal State Budgetary Educational Institution of Higher Education «Vyatka State Agricultural Academy» (Kirov, Russia).

\section{References}

1. V.I. Orobinsky, A.P. Tarasenko, A.M. Gievsky, A.V. Chernyshov, I.V. Baskakov, Advances in Engineering Research, 849-852 (2018) DOI: https://doi.org/10.2991/agrosmart-18.2018.159

2. V.I. Orobinsky, A.M. Gievsky, I.V. Baskakov, A.V. Chernyshov, Advances in Engineering Research, 870-874 (2018)

3. L.M. Schekleina, T.K. Sheshegova, Theoretical and Applied Ecology, 1, 5-12 (2013) DOI: http://doi.org/10.25750/1995-4301-2013-1-005-012 (In Russ.)

4. T.K. Sheshegova, L.M. Schekleina, E.I. Utkina, Agricultural science of the Euro-North-East, 65(4), 30-35 (2018) DOI: https://doi.org/10.30766 / 2072-9081.2018.65.4.30-351 (In Russ.)

5. L.M. Schekleina, T.K. Sheshegova, Bulletin of Mari State University, 2(14), 83-90 (2018) DOI: https://doi.org/10.30914 / 2411-9687-2018-4-2-83-89 (In Russ.)

6. L.M. Schekleina, Agricultural science of the Euro-North-East, 20(2), 134-143 (2019) DOI: https://doi.org/10.30766/2072-9081.2019.20.2. 134-143

7. T.K. Sheshegova, L.M. Schekleina, V.P. Zhelifonova, T.V. Antipova, B.P. Baskunov, Mycology and phytopathology, 53(3), 177-182 (2019) DOI: https://doi.org/10.1134 / S0026364819030127 
8. T.K. Sheshegova, I.N. Schennikova, L.M. Schekleina, L.P. Kokina, Agricultural Science of the Euro-North-East, 54(45), 9-14 (2016) DOI: https://doi.org/10.30766/2072-9081.2016.54.5.09-14

9. T.K. Sheshegova, G.A. Batalova, L.M. Schekleina, I.I. Rusakova, Agricultural Science of the Euro-North-East, 53(4), 10-14 (2016) DOI: https://doi.org/10.30766/20729081.2016.53.4.10-14

10.V.I. Orobinsky, A.M. Gievsky, A.P. Tarasenko, A.V. Chernyshov, Bulletin of the Voronezh State Agrarian University, 12 62(3), 13-18 (2019) DOI: https://doi.org/10.17238/issn20712243.2019.3.13

11.A.M. Gievsky, V.A. Gulevsky, V.I. Orobinsky, Bulletin of the Federal State Educational Establishment of Higher Professional Education "Moscow State Agroengineering University named after VP Goryachkin", 3(85), 12-16 (2018) DOI: https://doi.org/10.26897 / 1728-79362018-3-12-16

12.A.M. Gievsky, V.I. Orobinsky, A.P. Tarasenko, A.V. Chernyshov, D.O. Kurilov, IOP Conference Series: Materials Science and Engineering, 327, 042035. (2018) DOI: https://doi.org/10.1088/1757-899X/327/4/042035.

13. V.L. Andreev, IOP Conference Series: Materials Science and Engineering International Workshop «Advanced Technologies in Material Science, Mechanical and Automation Engineering», 32097 (2019) DOI: https://doi.org/10.1088/1757-899X/537/3/032097

14. V.I. Orobinsky, A.M. Gievsky, A.P. Tarasenko, A.V. Chernyshov, I.V. Baskakov, Bulletin of the Voronezh State Agrarian University, 12, 61(2), 34-42 (2019) DOI: https://doi.org/10.17238/issn2071-2243.2019.2.34

15. V.E: Saitov, R.F. Kurbanov, A.N. Suvorov, Procedia Engineering, 150, 107-110 (2016) DOI: https://doi.org/10.1016/j.proeng.2016.06.728

16. P. Savinyh, Y. Sychugov, V. Kazakov, S. Ivanovs, Engineering for Rural Development: 17th International Scientific Conference Engineering for Rural Development, Proceedings, 124-130 (2018) DOI: https://doi.org/10.22616/ERDev2018.17.N156

17. Yu.I. Ermoliev, A.A. Doroshenko, S.V. Belov, Bulletin of the Don State Technical University, 16. 85(2), 59-68 (2016) DOI: https://doi.org/10.12737 / 19691

18. V.E: Saitov, V.G. Farafonov, R.G. Gataullin, A.V. Saitov, IOP Conference Series: Materials Science and Engineering, 473, 012009 1-6 (2018) DOI: https://doi.org/10/1088/1757-899X/457/1/012009

19. K.D. Astanakulov, Y.Z. Karimov, G. Fozilov, AMA, Agricultural Mechanization in Asia, Africa and Latin America, 42(4), 37-40 (2011)

20. A. Saitov, R. Gataullin, V. Saitov, A machine for separating ergot from rye seeds, Patent RF, no. 2689470 (2019)

21. V.E. Saitov, V.G. Farafonov, A.V. Saitov, Agricultural Science of the Euro-NorthEast, 20(4), 407-419 (2019) DOI: https://doi.org/10.30766/2072-9081.2019.20.4.407419

22. V.A. Sysuev, V.E: Saitov, V.G. Farafonov, A.N. Suvorov, A.V. Saitov, Russian Agricultural Sciences, 43(3), 273-276 (2017) DOI: https://doi.org/10.3103/S1068367417030156 